\title{
eCommons@AKU
}

December 2008

\section{Understanding children's play}

Nilofar Vazir

Aga Khan University, Institute for Educational Development, Karachi

Syeda Imrana Raza

Aga Khan University, Institute for Educational Development, Karachi

Follow this and additional works at: http://ecommons.aku.edu/pakistan_ied_pdck

Part of the Educational Administration and Supervision Commons, and the Pre-Elementary, Early Childhood, Kindergarten Teacher Education Commons

\section{Recommended Citation}

Vazir, N., \& Raza, S. I. (2008, December). Understanding children's play. Nurture, (5), 3-6. 


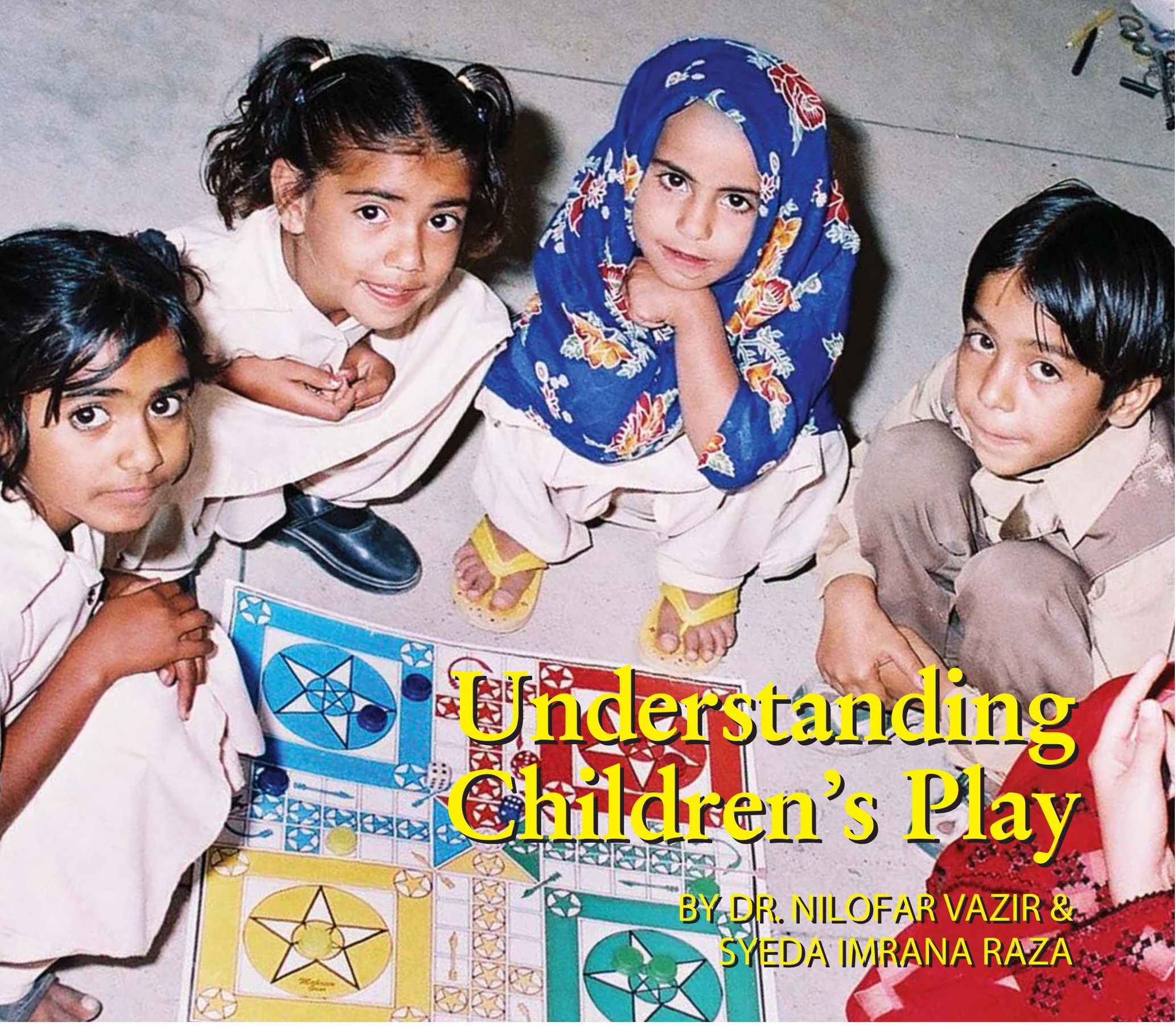

P lay is a critical activity in every child's life which serves as a way for children to develop an understanding about themselves, their world and their experiences; personal and that of peers. Every child instinctively needs to play as play gives children the freedom to imagine, promotes concept formation, associations and classifications, and encourages them to explore and to be creative. Moreover play enhances their social and intellectual competencies through providing opportunities for exploration, experimentation and manipulation of the environment.

Play is a dynamic process that develops and changes as it becomes increasingly varied and complex. It is a key facilitator for learning and development across various domains and reflects the social and cultural context in which children live. Play enhances multiple areas of children's development such as cognition, language, socialization and control over their emotions. Through play, children expand their understanding of themselves and others, their knowledge of the physical world, and their ability to communicate with peers and adults. Moreover, play promotes personal and social values such as empathy, trust, respect, love and care and admiration leading the child towards self-awareness and other human inter-relations.

Children are mentally very active and while playing they are constantly trying to make sense from the information they are processing. This provides children an outlet to express their emotions, feelings and ideas as well as a sense of accomplishment through achieving tasks in any given play situation. Play has therefore been given fundamental importance in the early childhood learning methods and teaching since learning through play and activities tends to maintain the interest and concentration of young learners.

\section{Play and Child Development}

Play is both a process and a product; as a process, play facilitates individual understanding of skills, concepts 
and dispositions; as a product, it provides a vehicle for children to demonstrate their understanding, skills and dispositions. Play continues in one form or the other from childhood into adulthood.

As children play, they learn all about themselves and what they can do. Play occurs throughout life but its form varies as children grow older. It directly offers opportunities to children to learn about their own selves, others and the environment in which they are living and growing. Children's play also has a significant impact on their developmental growth and contributes to their social adaptation from infancy to middle childhood. Play helps them make friends, enjoy company and discover the world around them. Play also facilitates personality integration and inner growth and enables children to understand and accept individual differences and multicultural issues in their interactions with others.

\section{Play at Different Developmental Stages}

Play is not only children's unique way of learning about their world, but also their way of learning about themselves and how they fit into the world. To best understand the relationship of children's play to learning and development one must be conversant with the characteristics that describe how play enhances all children's learning and development at different ages:

Infants and toddlers engage in activities that stimulate their senses and develop motor skills. This stage is the sensory motor stage, which involves senses and movement. Babies and toddlers actively explore objects and their own capabilities through simple, non goaloriented and repetitive play. Even within speaking distance of others, toddlers make little or no effort to communicate and when playing with similar toys may pursue unrelated activities.

At this stage children concentrate on their own needs, reflecting egocentric behaviour, and have no concept of rules. Such play contributes to infants' and toddlers' growing ability to pay attention and to the development of physical skills, social competence, and intellectual growth.

Young preschoolers play with other children, talk about common activities, and borrow or share toys. At this stage play is more pretend and imaginative with no explicit goals, nor do children make an effort to establish rules. Moreover young preschoolers do not find it easy to severe thought from an object and can barely separate the meaning of words from what they represent. They independently act and represent what they see through their imaginative play, hence, linking imagination with language development. Older preschoolers on the other hand play together and help each other in activities that produce some material or product or pursue some goal. They playfully re-enact events and change details to match personal needs and desires; this kind of play is with object and people.

Through play, preschoolers develop and refine motor skills, experience the joy of mastery, and develop and use basic academic skills such as counting, reading, and writing. Although they may imitate codified rules, their concepts of rules are individual and they make no attempt to win.

In the primary grades, children play formal and informal games with their peers (e.g., hopscotch; jump rope; board, card, and computer games). This kind of play enhances their coordination and physical competence, refines their

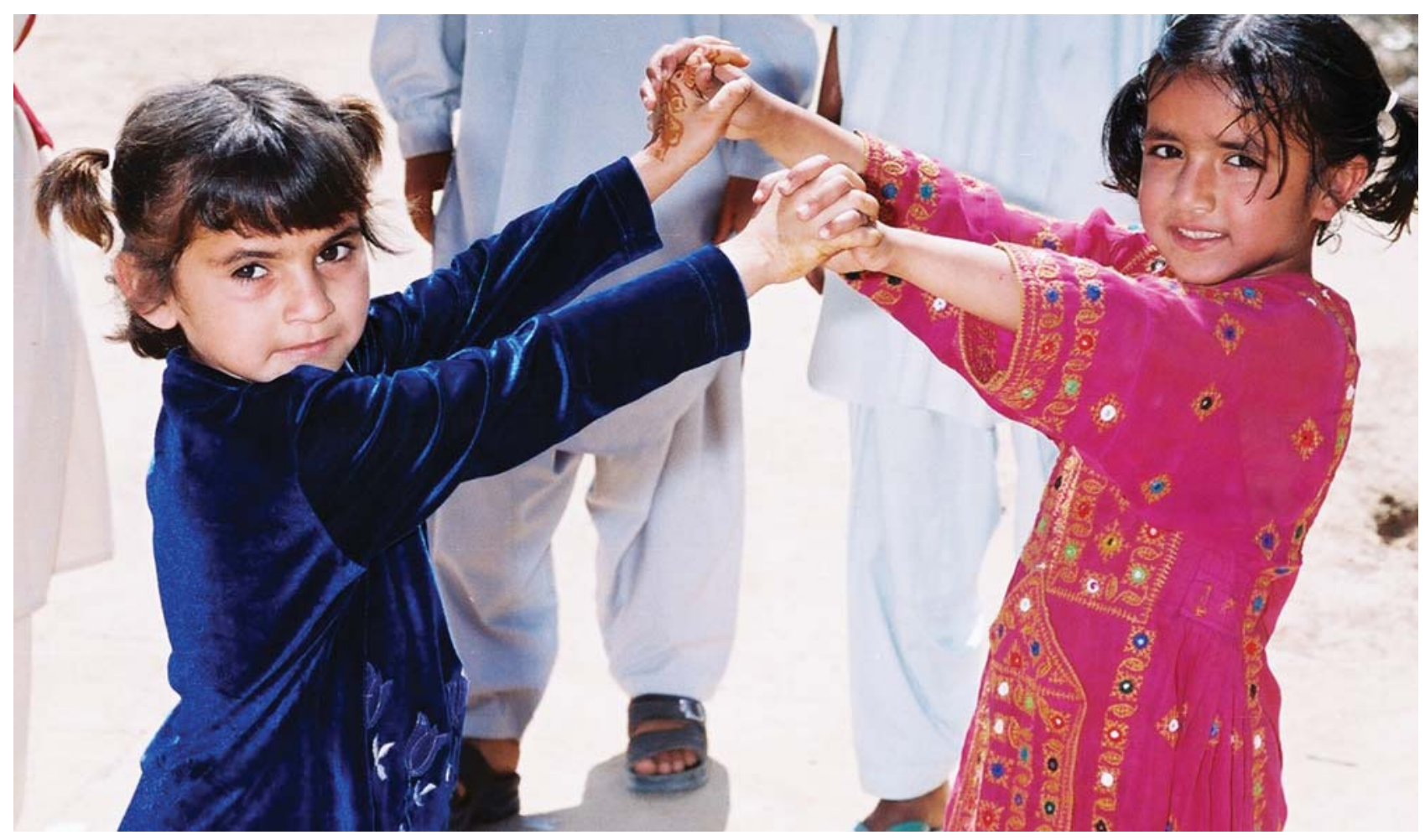


social skills, and builds concepts such as cooperation and competition, and enables them to demonstrate to themselves and to others their skills, talents, and abilities. At this stage, children like to explore and to create their own games, through riddles; number games, and secret codes. They also practice and demonstrate their growing understanding of word meanings, letter meanings, and numbers.

In later childhood and early adolescence, children's play is more organized and structured as their passion for orderly thinking manifests itself through games with rules and in organized sports. Winning becomes important for them as they begin to internalize that winning means following the rules. This is the age when team sports become important. Children grow in social awareness, their focus moves from the family and school to the peer group; and they want to be accepted in a social group. They can channelize their energies by joining various social groups, volunteer activities, and team sports. Through role taking and play in such organizations, they better understand how they will fit into the significance and structure of their social, political, and economic systems.

\section{Supportive Role of Adults in Children's Play}

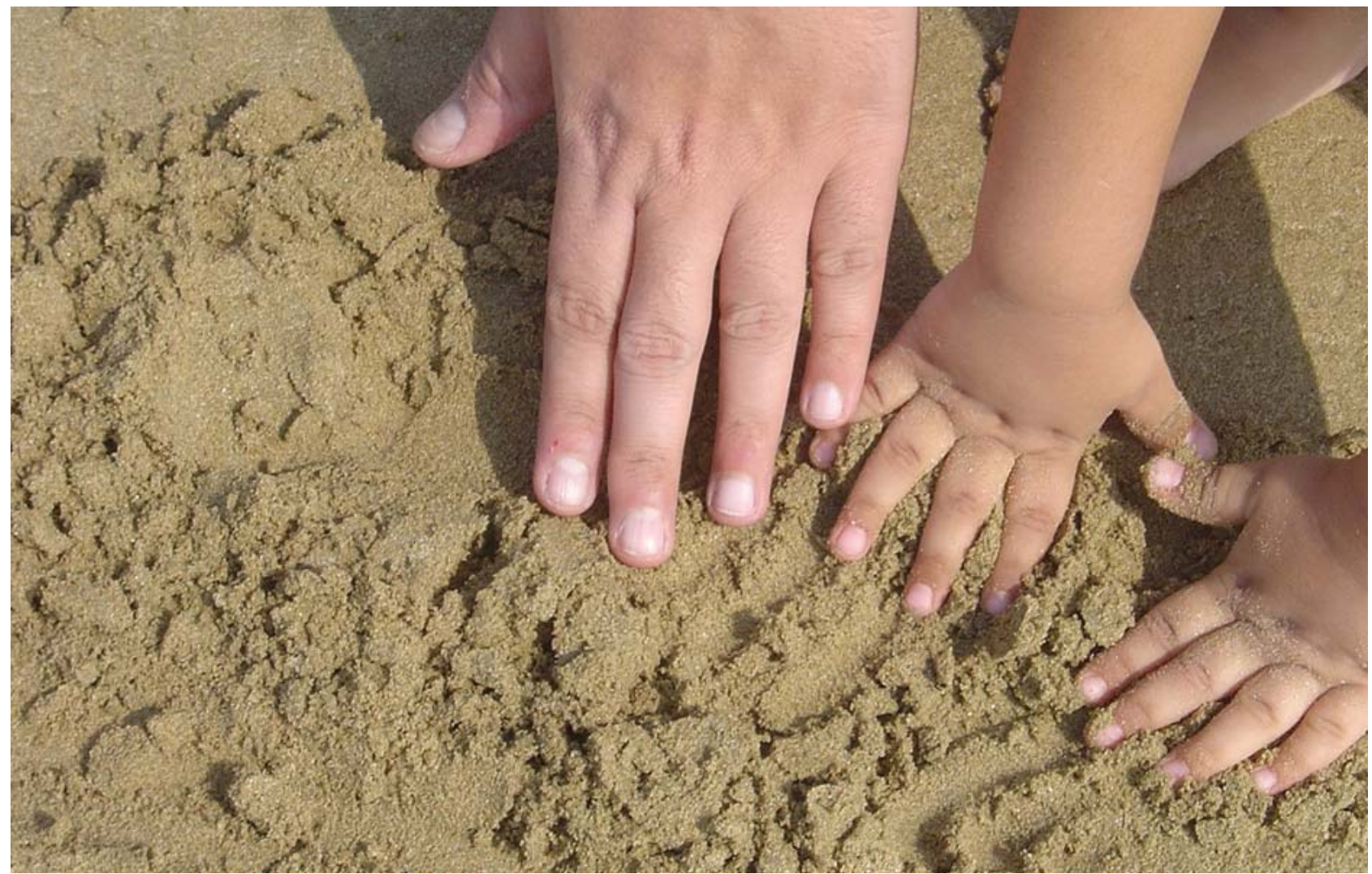

Caregivers occupy a key role in providing successful play opportunities for children in their early years. As supportive adults they need to understand those aspects of learning-rich play that do not change across the years of early childhood including the continuing need for time, resources, space and companions. Ensuring a developmentally appropriate play experience therefore remains a key for helping children to socialise and acquire vital coping skills as well as enhance their creativity and critical thinking.

For meaningful play to happen, adults must ensure the provision of play materials, adequate time, equal opportunity, on-going support, and freedom for children to explore and make independent choices. These experiences help children to grow and develop as healthy individuals.
For adults having opportunities to play with children, it is important to understand the right balance by intervening in play at the right moments as needless meddling can potentially become interference in the child's learning. An experienced person will usually be able to sense when to stand back and observe the play and when to become involved. Generally play is instinctive and children express a desire as to what they want to play with or at, and their interest is driven by choice and motivation. The nature, time duration and type of play thus needs to be sensitive to the individual needs or differences amongst young children.

Parental involvement and early childhood programmes that are play oriented are hence critical in the field of early years learning because they support children's growth and development, and encourage them to learn in a variety of ways. 


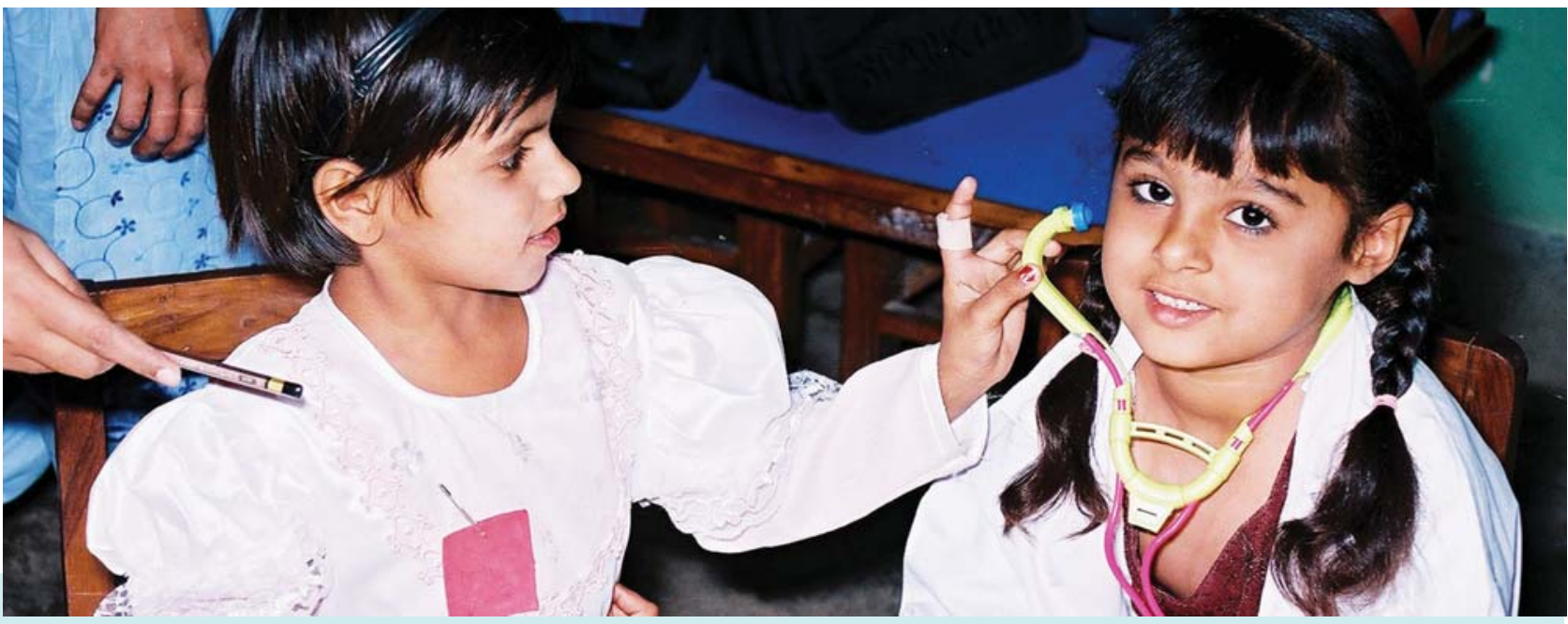

\section{Different Forms of Play}

Some consider play to be trivial and simple, and even a waste of time. On the contrary play is not wasted time but rather time spent building new knowledge from previous experience. Children may engage in play, because the activity is freely chosen, pleasurable and process-oriented. [Perhaps] goals are flexible, self-imposed, and may change during the course of the play; children are not bound by rules in their play, which may take many directions. This establishes that children are constructing their learning during play whether play is functional, constructive, symbolic, parallel, solitary, cooperative, socio-dramatic or pretend, play by self or with other children.

Play enhances children's freedom of imagination, promotes concept formation, associations and classifications, and encourages them to explore and to be creative as well as contributes to their brain development. It has also been widely emphasized that play helps in the development of a child's personality; as children play they deal with competition, fear, power, loneliness, acceptance, rejection and many other feelings. Children thus tend to shift their role easily from being social to anti-social and may use one or many forms of play simultaneously, for example, shifting from solitary to cooperative play.

Play can be divided into two different categories: (a) free play and (b) structured play

Free play takes place when the child is leading the play experience, sets out the rules and boundaries. This type of play will often hold the child's interest longer and she/ he can become engrossed in the activity because she/ he developed it her/ himself.

Structured play is adult led, guided and planned. Structured play tends to be more limiting and minimizes the child opportunities to be inventive.

Play is therefore one of the best ways for children to learn, whether it's a planned activity or free play (where there's no plan) and each child plays at his/ her own pace. A cornerstone of good early years practice is that children be encouraged through a balance of free and structured play routines.

\section{About the Writers:}

Author: Dr Nilofar Vazir Aziz is currently an Associate Professor and Coordinator of ECED Programmes at AKU-IED. She is associated with the field of education for more than thirty years. She has vast experience in teacher education, curriculum studies and qualitative research methods, particularly childhood research.

Co-Author: Ms Syeda Imrana Raza is currently an Instructor at AKU-IED. She has been involved since three years in facilitating ECED field based teachers training programmes at different levels and other ECED initiatives at university level.

Sources:
Educational Research Foundation.

Bruce, T. (2004). Developing learning in early childhood (0-8 years). London: Paul Chapman Company.

Dunn, J. (1993). Young children's friendships. In Young children's close relationship: Beyond attachment, 58-73. London: Sage. 